\title{
Teacher's Attitudes and Strategies when Schoolchildren Need to Go to the Toilet
}

\author{
Barbro Lundblad ${ }^{1}$, Marie Berg ${ }^{1}$ and Anna-Lena Hellström ${ }^{2}$ \\ 1. Institute of Health and Care Sciences, Sahlgrenska Academy at University of Gothenburg, Göteborg SE 405 30, Sweden \\ 2. University of Gothenburg Centre for Person-centred Care, Institute of Health and Care Sciences Sahlgrenska Academy at \\ University of Gothenburg, Göteborg SE 405 30, Sweden
}

\begin{abstract}
It is well known that a lot of children avoid going to the toilet during school. This is mainly due to poor hygienic standards in the toilets but also due to fear and insecurity when visiting the toilet during recess. Studies show that children are not always allowed to go to the toilet during class and that many teachers decide when the children may satisfy their toilet needs. The purpose of this study was to describe teacher's attitudes and strategies when schoolchildren need to go to the toilet. Interviews with 17 teachers working in five Swedish compulsory schools. The teacher's attitudes were that the physiological need or children's will should determine when they could go to the toilet and that children have different toilet needs. All teachers used rules to regulate toilet visits during class. The rules were not communicated and required the interpretation of the children. The teachers demanded openness and information about the toilet needs of the children. Suspected misuse of toilet visits led the teacher to make their own assessment of the children's toilet needs, as a sanction toilet visits could be prohibited. The strategies used during class did not reflect the health-promoting attitude the teachers told about. In reality, the task of maintaining order and control was prioritised. The strategies used were not adapted to children's needs, which could have significance for maintaining toilet habits consistent with health and well-being.
\end{abstract}

Key words: Children, health, rules, school, teacher, toilet needs.

\section{Introduction}

It is well known that a lot of children avoid going to the toilet during school. Going to the toilet when the need occurs promotes health and well-being. Included in the school's task of conveying knowledge, is to work towards children acquiring a lifestyle and habits of life which is consistent with health [1]. Studies show that children are not always allowed to visit the toilet during class and that many teachers determine when they may go [2]. It is also known that rules for toilet visits create problems for children suffering from bladder disturbances whilst in school [3]. Information about teacher's attitudes to schoolchildren going to the toilet and the strategies used to manage these is almost non-existent.

Between the ages of five and six, most children have

Corresponding author: Anna-Lena Hellström, professor, research field: children's health and urinary bladder disturbances. achieved complete voluntary bladder control of voluntarily being able to alternate between holding and emptying the bladder [4]. It has been shown that children between 7 and 15 years of age, irrespective of gender, urinate 3-8 times a day and that the amount of urine which gives rise to emptying varies greatly. Some children empty the bladder when the full capacity of the bladder has been reached, while other children feel the need to go to the toilet with little bladder volume. For children in this age group, going to the toilet is to a great extent governed by behavioural and social reasons and to a lesser degree by the physical need [5]. A survey showed that $16 \%$ of schoolchildren never urinated in the school toilet [6]. Most of the younger schoolchildren defecate once or twice a day [7]. The aforementioned survey [6] showed that 63\% of schoolchildren never defecated in the school toilet. It is estimated that $15 \%$ of schoolchildren have some form of defective functional control. The actual number of 
affected schoolchildren is hard to measure, as far from all seek professional treatment [7-10].

Leadership in Swedish classrooms is still perceived as being a teacher's business which is therefore often built on the teacher's personal education culture [11]. One of the tasks for teachers is to develop standards for acceptable behaviour, and rules can support teachers in maintaining order in the classroom [12]. Thornberg [13] categorised rules in schools. The category "Structuring rules" contained rules that were aimed at structuring and maintaining activities that take place in school. According to Burden [14], classroom rules must, regardless of the aim, always protect the rights of the teachers and pupils and through the use of rules should not be either physically or psychologically harmed.

The purpose of this study was to describe teacher's attitudes and strategies when schoolchildren need to go to the toilet.

\section{Methods}

The study has a qualitative approach with individual interviews. Ethical consideration has been carried out in accordance with Declaration of Helsinki-Ethical principles for medical research involving human subjects.

\section{Subjects}

Seventeen teachers and two school leaders, are all with extensive experience in teaching and working in compulsory schools.

\subsection{Procedure}

After consultation with the administrative management for school healthcare, the rectors of five compulsory schools in Gothenburg, Sweden were contacted by post about the study and its aim. Following a positive answer the respective school nurses were contacted. With written and verbal information about the study they then asked the school's teachers if they were interested in participating.

\subsection{Instruments}

An interview guide comprising five open-ended questions became the basis for the interviews.

Time and place for the interviews were decided by the teachers (Table 1). The teachers were reassured that the interviews would be confidential and that the data and results would be anonymous. The interviews were conducted in each of the five schools and individually performed. They lasted approximately $20 \mathrm{~min}$ and were tape-recorded.

\subsection{Data Analysis}

The interviews were transcribed to text and the respondent's identification was removed.

The analysis followed the criteria developed by Krippendorff [16]. First, all text was read several times to obtain an overall impression. Thereafter, meaning units were identified and condensed from the text, this could be single words, parts of and whole sentences. During the next step, meaning units were coded from which eight sub-categories were identified and clustered into two categories describing the content. During the whole analytic process there was an alteration between the text as a whole and parts. This made it possible to validate the identified categories and to redefine them if necessary. All three authors were engaged in this process. An example of the analytic process is illustrated in Table 2 .

Table 1 Interview guide of open-ended interview questions given to the respondents.

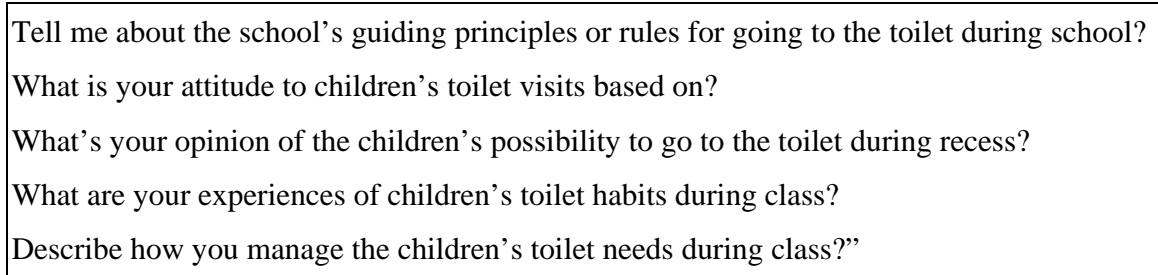


Table 2 Example of analytic process.

\begin{tabular}{|l|l|l|l|l|}
\hline Meaning unit & Condensation & Code & Sub-category & Category \\
\hline $\begin{array}{l}\text { I have children of my own } \\
\text { who have to go to the } \\
\text { toilet when they need to }\end{array}$ & $\begin{array}{l}\text { Own children must go } \\
\text { when they need to }\end{array}$ & Own children & $\begin{array}{l}\text { Based on personal } \\
\text { experiences }\end{array}$ & $\begin{array}{l}\text { Attitude to children's } \\
\text { needs to go to the toilet }\end{array}$ \\
\hline $\begin{array}{l}\text { It's important to go when } \\
\text { you need to }\end{array}$ & Go when you need to & Go when you need to & $\begin{array}{l}\text { Toilet visits should be } \\
\text { ruled by the need }\end{array}$ & $\begin{array}{l}\text { Attitude to children's } \\
\text { needs to go to the toilet }\end{array}$ \\
\hline $\begin{array}{l}\text { More and more want to go } \\
\text { during class }\end{array}$ & Want to go during class & Want to go during class & $\begin{array}{l}\text { Perception of children's } \\
\text { toilet habits }\end{array}$ & $\begin{array}{l}\text { Attitude to children's } \\
\text { needs to go to the toilet }\end{array}$ \\
\hline $\begin{array}{l}\text { Scared that someone } \\
\text { could come in }\end{array}$ & Someone could come in & Someone could come in & $\begin{array}{l}\text { Know that going to the } \\
\text { toilet creates problems } \\
\text { for children }\end{array}$ & $\begin{array}{l}\text { Attitude to children's } \\
\text { needs to go to the toilet }\end{array}$ \\
\hline Haven't ever said it & Never said it & Not verbally expressed & $\begin{array}{l}\text { Use rules which require } \\
\text { interpretation }\end{array}$ & $\begin{array}{l}\text { Strategies with children's } \\
\text { need to go to the toilet }\end{array}$ \\
\hline Curb toilet visits to recess & Curb toilet visits & Curb toilet visits & $\begin{array}{l}\text { Manage toilet with aid of } \\
\text { rules }\end{array}$ & $\begin{array}{l}\text { Strategies with children's } \\
\text { need to go to the toilet }\end{array}$ \\
\hline I ask for a reason & Ask for reason & Requests reason & $\begin{array}{l}\text { Demand openness about } \\
\text { toilet needs }\end{array}$ & $\begin{array}{l}\text { Strategies with children's } \\
\text { need to go to the toilet }\end{array}$ \\
\hline $\begin{array}{l}\text { It depends which pupil it } \\
\text { is }\end{array}$ & It depends which it is & Depends on which it is & Assess the toilet need & $\begin{array}{l}\text { Strategies with children's } \\
\text { need to go to the toilet }\end{array}$ \\
\hline
\end{tabular}

\section{Results}

The category, which shows attitude, was based on the teacher's personal and professional experiences, observations and feelings.

The other category shows the teacher's strategies, the purpose of them as well as how they were used.

\subsection{Attitude to Children's Needs to Go to the Toilet}

\subsubsection{Based on Personal Experience}

The attitude to children's need to go to the toilet was based on own or family member's experiences. Frequently, memories from own school days were used as a guide; "You just have to turn to your own experiences”, "I actually relate to myself a bit”, "I have children, they have to go when they need to".

Hearsay could also be the basis for the attitude to the toilet visit such as damage, discomfort and other effects that could be a consequence of not going to the toilet; “It's not good to go with an overfull bladder”, “It's not good to have an accident with a full bladder".

\subsubsection{Toilet Visits should be Ruled by the Need}

Central for the teachers was the time for the toilet visit being ruled by the physiological need or by the individual's will. "It's important to go when you need to", "When you want to go, you should go". The importance of showing respect for children's toilet needs was apparent and that toilet visits should be seen as one of many personal needs. The freedom of the individual to decide when they should go to the toilet was emphasized and was connected with the difficulty of not accepting a need to go to the toilet. Teachers believed that children must learn to adapt their visits to the toilet as they get older; "Each child's individual needs include going to the toilet", "Essential to have the freedom to go", "It's hard to say no", "When they get to about twelve years old, they have to start thinking and planning”.

\subsubsection{Perception of Children's Toilet Habits}

None of the teachers had a clear perception of whether the children went to the toilet during school. This was often built on the experience they had of children who needed to go to the toilet during class; "More and more want to go during class". They had however, noted that children's toilet needs differed; "Some hold themselves all day", "Some go all the time”.

There was a widespread understanding among the teachers that a pupil's request to be allowed to go to the toilet was often a masked desire to take a break from schoolwork. The interruption was seen as a chance to meet a friend or to satisfy a need of physical activity; "It's very easy to say I need to go to the toilet to get away for a while", "I understand that they use it 
because they maybe need a breath of fresh air", "Sometimes you suspect that it's to meet friends".

4.1.4 Know that Going to the Toilet Creates Problems for Children

There was awareness about the causes, which could affect children's toilet habits, and above all what could affect their choice of time for the toilet visit. Few teachers saw the hygienic standards in the school toilets as a significant factor. The reasons could also be related to children's desire for privacy and not being disturbed in the toilet. There were, according to teachers, children who, particularly the older ones, felt uneasy about going to the toilet as they felt embarrassed by the need to go to the toilet. Children's fears in connection with going to the toilet were also highlighted. The teachers considered this to be due to children waiting outside knocking or pulling on the door and that the children were scared of being seen during their toilet visit. Too little time during recess was, according to the teachers another underlying cause; "Scared that someone could come in", "Older children think it's embarrassing”, "Quieter during class”.

\subsection{Strategies with Children's Need to Go to the Toilet}

\subsubsection{Use Rules that Require Interpretation}

None of the teachers interviewed, knew if there was any written or verbal common policy or rules to meet the children's toilet needs during school. Neither was this shown to be a subject for discussion among the teachers. However, it became apparent that the children were expected to have carried out their toilet needs during recess; “There aren't any general school rules about going to the toilet", "Don't know if there are any", "You want them to go during recess but they don't”.

Only a few teachers had informed the children in their class about the routine they wanted to follow when someone needed to go to the toilet during class. The rest of the teachers had no recollection of ever having talked to the children about going to the toilet. A lot of the teachers stated, that in time the children learnt the routines for going to the toilet by observing what other children did, or by interpreting what the teacher wanted; "Haven’t ever said it”, "It just became that way", "The children learn what the teacher wants", "The children go with the flow".

There were teachers who saw difficulties with written and articulated rules for going to the toilet as they could feel restricting.

\subsubsection{Manage Toilet Visits with the Aid of Rules}

During teacher-centred teaching and during tests, toilet visits were in principle not allowed. It was important for the teachers that all the children listened to the teacher's instruction and the information, which was given prior to exercises the children, should carry out on their own. A toilet visit was sometimes considered disruptive, mainly for the teachers but also for the pupils. The children's toilet visit was more often than not set to the time during class when the children had to work on their own assignments. An exception to the rule was only given if the child could give a credible reason. Being in an absolute emergency situation was the reason many used all the time; "When I speak, everyone should listen", "They have to wait until I'm finished", "Curb toilet visits to recess".

\subsubsection{Demand Openness about Toilet Needs}

How the children's toilet needs were managed was dependent on the teacher's personality, the present situation, or the age of the child; "It's different from person to person", "Depends on the lessons", "You have to go with your instincts", "If you've had recess, you have only yourself to blame".

A mutual requirement for allowing a visit to the toilet was that the child should inform the teacher about his/her toilet need. The information should normally be preceded by the child raising his/her hand, catching the teacher's attention and await permission to inform the teacher of their situation. Some teachers wanted the information formulated in such a way as to clarify that they alone decided if and when a child could use the toilet. Others gave the children the possibility of approaching the teacher and in this manner inform 
about their situation; “They have to tell us", "They put their hand up and ask for permission”, "I ask for a reason", "They can come forward and ask".

\subsubsection{Assess the Toilet Need}

Some teachers could, after a short time, identify the children who had previously used going to the toilet as a pretext for another activity. For the individual child this could mean that the teacher made an assessment of their toilet needs and could also be totally prohibited from going to the toilet during class. Some teachers did not regard sanctions as the first alternative but every situation should be assessed and that misuse required a talk with the child; "There are students who always say they have to go to the toilet but you soon learn who they are and that it's not actually a need to go to the toilet but something else", "If they're sitting in the common room, they're done, they don't get to go to the toilet”, "It depends which pupil it is".

\section{Discussion}

The approach of these seventeen teachers, that the physiological need and desire to go to the toilet should determine the time for the visit, conforms well to the view what is the basis for health promotion. Emptying the bladder when the body signals the need is a cornerstone in the treatment of functional disturbances and children are encouraged to acquire this procedure and make it a habit [17].

All of the teachers had experience of pupils needing to go to the toilet during class and the reasons attributed to this; insecurity and anxiety, often connected to the risk of infringement of integrity that children could experience when going to the toilet during recess. It was open for every teacher to manage the children's toilet needs as they wished. The fact that only a few had any recollection of informing or discussing their rules for going to the toilet with the pupils is notable, according to children's rights they have to be heard in issues that affect their environment [18].

In practice all of these teachers had chosen to use rules for going to the toilet. With the support of the categorising of rules according to Thornberg [13], it was shown that these teachers mainly used "Structuring rules". The purpose of using this type of rules was to regulate the children's toilet visits and to meet the need to control the pupils. To make it difficult for children when they need to go to the toilet is not coherent with the health-promoting attitude the teachers had or to forbid bladder and bowel emptying. For a child in need it can be experienced as physical punishment. Not knowing for sure if and when you are allowed to go to the toilet has been shown to create anxiety in children with bladder problems [3]. One can presume that this anxiety can also affect children who do not have an obvious problem, but who because of psychological and social reasons wait to go to the toilet until the toilets are quiet, which is during class. Mattsson et al [5] have shown that schoolchildren often choose a time for going to the toilet based on social reasons that was also shown to be the teacher's understanding. A number of teachers in this study taught senior level where all the children are teenagers. Teenagers have a great need for privacy, particularly in situations where their bodies and its needs risk being exposed [19]. That the pupil must raise his/her hand, wait their turn to speak and then ask for permission to satisfy their toilet need occurs relatively often with these teachers. The consequence is that the child's private toilet needs are automatically shared with all their classmates. This shows with the desired clarity the importance of rules being used selectively and that an uncritical use can entail risks for the health and well-being of children [14].

\section{Study Strengths and Limitations}

For the aim of describing the teacher's personal attitudes and strategies, the qualitative research interview was considered a suitable method for data collection. During the interviews, the need for clarification sometimes became apparent, which due to the character of the questions, were of a more structural nature. According to Kvale [20], this interview method 
can be technically viewed as semi-structured, as it is usually carried out along with a predetermined interview guide. The respondents chose the time of the interview when they had a break that was not always optimal for conducting interviews.

\section{Conclusions}

The strategies used during class did not reflect the health-promoting attitude the teachers told about. In reality, order and control was often prioritised. The regulations used were set by the teachers themselves and were not communicated to the children neither was the significance for the children taken into account. As the strategies are not adapted to children's needs it could have significance for maintaining toilet habits consistent with health and well-being. The results show there is a need to value the use of classroom rules for toilet visits from a health perspective.

\section{References}

[1] Curriculum for the Compulsory School System, the Pre-School Class and the Leisure-time Centre. Lpo 94. Available at: http:// www.skolverket.se [Swedish National Agency for Education]. Accessed; 1994.

[2] Boyt, M. A. 2005. “Teachers' Knowledge of Normal and Abnormal Elimination Patterns in Elementary School Children.” J. Sch. Nurs. 21: 346-9.

[3] Lundblad, B., Berg, M., and Hellström, A. L. 2007. "Experiences of Children Treating Functional Bladder Disturbances on Schooldays.” J. Pediatr. Urol. 3: 189-93.

[4] Jansson, U. B., Hansson, M., Sillén, U., and Hellström, A. L. 2005. "Voiding Patterns and Acquisition of Bladder Control from Birth to the Age of 6 Years-A Longitudinal Study.” J. Urol. 174: 289-93.

[5] Mattsson, S., Gladh, G., and Lindström, S. 2003. "Relative Filling of the Bladder at Daytime Voids in Healthy School Children.” J. Urol. 170: 1343-6.

[6] Lundblad, B., and Hellström, A. L. 2005. "Perceptions of School Toilets as a Cause for Irregular Toilet Habits
Among School Children Aged 6 to 16 Years.” J. Sch. Health 75 (4): 125-28.

[7] Yong, D., and Beatti, R. M. 1998. "Normal Bowel Habit and Prevalence of Constipation in Primary-school Children.” Ambul. Child Health 4: 277-82.

[8] Mattsson, S. 1994. "Urinary Incontinence and Nocturia in Healthy Schoolchildren.” Acta Paediatr 83: 950-4.

[9] Hansen, A., Hansen, B., and Dahm, T. L. 1997. "Urinary Tract Infection, Day Wetting and Other Voiding Symptoms in Seven to Eight-year-old Danish Children.” Acta Paediatr 86: 1345-9.

[10] Bakker, E., van Sprundel, M., Van der Auwera, J. C., Van Gool, J. D., and Wyndaele, J. J. 2002. "Voiding Habits and Wetting in a Population of 4,332 Belgian Schoolchildren Aged between 10 and 14 years.” Scand. J. Urol. Nephrol. 36: 354-62.

[11] Granström, K. 1988. "Swedish Classroom Rhetoric and Practice.” In: Shimara NK ed, Politics of Classroom Life: Classroom Management in International Perspective. New York: Garland Publishing Inc; 137-62.

[12] Jones, V. F., and Jones, L. S. 2004. Comprehensive Classroom Management: Creating Communities of Support and Solving Problems. Boston: Pearson Education.

[13] Thornberg, R. 2008. "A Categorisation of School Rules.” Educational Studies 34 (1): 33.

[14] Burden, P. R. 2000. Powerful Classroom Management Strategies: Motivating Students to Learn. Thousand Oaks: Corwin Press Inc.

[15] Svensk författningssamling. SFS: 2003: 460. [The act concerning the Ethical Review of Research concerning Humans]. Stockholm: Fritzes.

[16] Krippendorff, K. 2004. Content Analysis. An introduction to Its Methodology. London: Sage.

[17] Abrams, P., Cardozo, L., Khoury, S., and Wein, A. 2005. “Incontinence: Basics \& Evaluation.” In: Proceedings of the 3rd International Consultation on Incontinence, 26-29 June 2004. Vol. 2, Chapter 16. Plymouth, MN: Health Publication Ltd.

[18] United Nations. Convention on the Rights of the Child Document (A/RES/44/25) 1989.

[19] Hutton, A. 2002. "The Private Adolescent: Privacy Needs of Adolescents in Hospitals.” J. of Pediatric Nurs. 17 (1): 67-72.

[20] Kvale, S. 1996. Interviews. Thousand Oaks: Sage. 